\title{
Optimal Treatment Strategy in Rectal Cancer Surgery: Should We Be Cowboys or Chickens?
}

\author{
Heleen S. Snijders, $\mathrm{MD}^{1}$, Nicoline J. van Leersum, $\mathrm{MD}^{1}$, Daan Henneman, $\mathrm{PhD}^{1}$, Alexander C. de Vries, $\mathrm{MD} \mathrm{PhD}^{2}$, \\ Rob A. E. M. Tollenaar, MD, $\mathbf{P h D}^{1}$, Anne M. Stiggelbout, $\mathbf{P h D}^{3}$, Michel W. J. M. Wouters, $\mathrm{MD}, \mathbf{P h D}^{4}$, and \\ Jan Willem T. Dekker, MD, PhD $^{5}$
}

${ }^{1}$ Department of Surgery, Leiden University Medical Centre, Leiden, The Netherlands; ${ }^{2}$ Department of Surgery, Medical Center Haaglanden, The Hague, The Netherlands; ${ }^{3}$ Department of Medical Decision Making, Leiden University Medical Center, Leiden, The Netherlands; ${ }^{4}$ Department of Surgery, Netherlands Cancer Institute-Antoni van Leeuwenhoek Hospital, Amsterdam, The Netherlands; ${ }^{5}$ Department of Surgery, Reinier de Graaf Gasthuis, Delft, The Netherlands

\begin{abstract}
Background and Purpose. Surgeons and hospitals are increasingly accountable for their postoperative complication rates, which may lead to risk adverse treatment strategies in rectal cancer surgery. It is not known whether a risk adverse strategy leads to providing better care. In this study, the association between the strategy of hospitals regarding defunctioning stoma construction and postoperative outcomes in rectal cancer treatment was evaluated. Methods. Population-based data of the Dutch Surgical Colorectal Audit, including 3,104 patients undergoing rectal cancer resection between January 2009 and July 2012 in 92 hospitals, were used. Hospital variation in (case-mix-adjusted) defunctioning stoma rates was calculated. Anastomotic leakage and 30-day mortality rates were compared in hospitals with a high and low tendency towards stoma construction.

Results. Of all patients, $76 \%$ received a defunctioning stoma; $9.6 \%$ of all patients developed anastomotic leakage. Overall postoperative mortality rate was $1.8 \%$. The hospitals' adjusted proportion of defunctioning stomas varied from 0 to $100 \%$, and there was no significant correlation between the hospitals' adjusted stoma and
\end{abstract}

Heleen S. Snijders and Nicoline J. van Leersum contributed equally to this work.

(C) The Author(s) 2015. This article is published with open access at Springerlink.com

First Received: 19 August 2014;

Published Online: 18 February 2015

H. S. Snijders, MD

e-mail: h.s.snijders@lumc.nl anastomotic leakage rate. Severe anastomotic leakage was similar ( 7.0 vs. $7.1 \% ; p=0.95)$ in hospitals with the lowest and highest stoma rates. Mild leakage and postoperative mortality rates were higher in hospitals with high stoma rates.

Conclusions. A high tendency towards stoma construction in rectal cancer surgery did not result in lower overall anastomotic leakage or mortality rates. It seems that the ability to select patients for stoma construction is the key towards preferable outcomes, not a risk adverse strategy.

Surgical resection is the cornerstone of rectal cancer treatment. If tumor size, stage, and location allow for a sphincter-preserving resection, and bowel continuity is restored, the surgeon has to decide whether or not to defunction the anastomosis. The advantage of a defunctioning stoma can be that it decreases the consequences of anastomotic leakage, and may also decrease its incidence. ${ }^{1,2}$ Anastomotic leakage is a serious complication causing reoperation, prolonged hospital stay, morbidity, mortality, and possibly worse oncological outcome ${ }^{3-5}$ On the other hand, a stoma has evident disadvantages; defunctioning stomas can induce morbidity, discomfort (decreased quality of life), higher costs, ${ }^{6}$ longer hospitalization, ${ }^{7}$ and even mortality from surgery to close the stoma ${ }^{8-12}$ Furthermore, $80 \%$ of defunctioning stomas are only reversed after 4 months, and $20 \%$ are never reversed. ${ }^{13}$

Nowadays, quality of care has become a major topic, and surgeons and hospitals are increasingly accountable for their postoperative complication rates. This may lead to risk adverse treatment strategies. Previous research suggests that differences in professional opinion may lead to variation in healthcare delivery ${ }^{14-21}$ The threshold for the 
decision to construct a stoma to avoid the risk for anastomotic leakage may also vary between surgeons. Some surgeons may be bigger risk takers or more risk adverse than others. However, attempts to avoid or limit the risk for anastomotic leakage after colorectal surgery by frequent use of stomas is only in the patient's interest if it in fact lowers clinically relevant anastomotic leakage and mortality rates.

The objective of this study was to investigate whether hospitals differ in their treatment strategy regarding construction of defunctioning stomas in rectal cancer surgery, and to assess if a hospital's treatment strategy is related to its postoperative outcomes, such as clinically relevant anastomotic leakage and mortality rates.

\section{METHODS}

\section{Study Cohort}

Data were derived from the Dutch Surgical Colorectal Audit (DSCA). The DSCA contains data registered by 92 hospitals (representing all hospitals performing colorectal cancer surgery in The Netherlands), and over $90 \%$ of all eligible patients are included. The dataset is disease-specific for colorectal cancer and has shown a nearly $100 \%$ concordance on most items upon validation against the Netherlands Cancer Registry dataset. ${ }^{22}$ All patients having undergone anterior resection for primary rectal cancer between 1 January 2009 and 31 July 2012 were evaluated. Minimal data requirements for inclusion in the analysis were information on tumor location, date of surgery, and mortality. Patients without an anastomosis, with metastasis at the time of primary surgery, resections for multiple synchronous colorectal tumors, and with a tumor less than $5 \mathrm{~cm}$ from the anal verge were excluded because these represent subgroups of patients with specific treatment perspectives and subsequent different expected outcomes.

\section{Definitions}

Overall anastomotic leakage, as used in the hospital comparisons, was defined as 'clinically relevant anastomotic leak requiring a re-intervention, either radiological (mild) or surgical (severe)'. Postoperative mortality was defined as 'in-hospital mortality or all deaths within 30 days after primary surgery'.

The following case-mix factors were considered: age, sex, American Society of Anesthesiologists (ASA) classification, abdominal surgical history, tumor height, preoperative tumor complications, and urgency of the resection. Considered treatment factors were surgical procedure (laparoscopic or open), and neoadjuvant treatment.
Hospitals were stratified into non-teaching and teaching hospitals. Procedural volume in rectal cancer resections was calculated for each hospital before the aforementioned exclusion of patients, and categorized into $<25,25-50$ and $>50$ resections per year.

\section{STATISTICAL CONSIDERATIONS}

As patient- and tumor-related case-mix factors may be responsible for a large part of the hospital variation in the proportion of patients with a defunctioning stoma, we adjusted for these differences by calculating the observed/expected $(\mathrm{O} /$ E) stoma rate. The observed outcome was the number of patients with a defunctioning stoma in a hospital, and the expected outcome was the sum of all patients' estimated probabilities for a defunctioning stoma. Patients' probability estimates were derived from a backwards stepwise multivariate logistic regression model, fitted on the data of all included hospitals, and using all case-mix factors mentioned above. For an average performing hospital, the observed outcome will be equal to the expected outcome, resulting in an $\mathrm{O} / \mathrm{E}$ outcome ratio of 1 . Hospitals that construct more defunctioning stomas than average have an $\mathrm{O} / \mathrm{E}$ outcome ratio higher than 1 , while this ratio is lower than 1 in hospitals with lower than average stoma rates.

The adjusted O/E ratios of the hospitals were plotted against their anastomotic leakage rates.

The relation between the hospitals' strategy and its outcomes was analyzed by two methods. First, to evaluate whether stoma rates were related to (lower) anastomotic leakage rates on a hospital level, a linear correlation was calculated using Pearson's correlation coefficient $R$. Second, to evaluate whether a risk adverse strategy (high stoma rates) is related to better postoperative outcomes on a hospital level, hospitals were grouped into equally-sized groups based on quintiles of their case-mix-adjusted rate of defunctioning stomas.

Differences between groups in outcomes (mild and severe anastomotic leakage and mortality rates) were analyzed using a Chi square test.

The association of patient- and tumor-related case-mix factors, hospital factors (teaching status, volume), and treatment factors (neoadjuvant therapy, laparoscopic surgery) with being in the high stoma group was assessed with a Chi square test and multivariate logistic regression analysis, considering the same case-mix factors as mentioned above. All statistical analyses were performed in PASW Statistics, IBM Corporation (previously SPSS Software, Armonk, NY, USA).

\section{RESULTS}

Between 1 January 2009 and 31 July 2012, a total of 92 hospitals registered all rectal cancer patients in the DSCA. 
TABLE 1 Patient, tumor, and treatment characteristics of included patients

\begin{tabular}{|c|c|}
\hline & $N(\%)$ \\
\hline Age [mean (range)] & $66(15-97)$ \\
\hline Male sex & $1,850(60)$ \\
\hline \multicolumn{2}{|l|}{ ASA classification } \\
\hline I-II & $2,567(83)$ \\
\hline III+ & $369(12)$ \\
\hline Missing & $168(5)$ \\
\hline Abdominal surgical history, yes & $808(26)$ \\
\hline \multicolumn{2}{|l|}{ Tumor location $(\mathrm{cm})$} \\
\hline$\geq 10$ & $1,149(14)$ \\
\hline$<10$ & $1,660(20)$ \\
\hline Urgency, acute/urgent & $57(2)$ \\
\hline \multicolumn{2}{|l|}{ Tumor stage } \\
\hline (Y) pT0/X & $207(7)$ \\
\hline pT1 & $269(9)$ \\
\hline pT2 & $990(32)$ \\
\hline pT3 & $1,533(49)$ \\
\hline pT4 & $105(3)$ \\
\hline \multicolumn{2}{|l|}{ Surgical preoperative treatment } \\
\hline Stoma & $162(5)$ \\
\hline Stent & $8(0.3)$ \\
\hline Other & $51(3)$ \\
\hline \multicolumn{2}{|l|}{ Neoadjuvant treatment } \\
\hline $5 \times 5$ Gy & $1,623(52)$ \\
\hline Chemoradiation & $825(27)$ \\
\hline \multicolumn{2}{|l|}{ Surgical procedure } \\
\hline Laparoscopic resection & $1,393(45)$ \\
\hline \multicolumn{2}{|l|}{ Hospital type } \\
\hline Teaching hospital & $2,175(70)$ \\
\hline Non-teaching hospital & $929(30)$ \\
\hline \multicolumn{2}{|l|}{ Hospital volume } \\
\hline High ( $>50 /$ year) & $875(28)$ \\
\hline Medium (25-50/year) & $1,490(48)$ \\
\hline Low $(<25 /$ year $)$ & $739(24)$ \\
\hline
\end{tabular}

ASA American Society of Anesthesiologists risk score

After exclusion of ineligible patients, a total of 3,104 patients were included in the analysis. Characteristics of the included patients and hospitals are shown in Table 1.

Overall, $67 \%(n=2,080)$ of all patients received an anastomosis with a defunctioning stoma.

In total, 302 patients $(9.6 \%)$ developed anastomotic leakage. The majority (187 of 302, $62 \%$ ) were severe leakages requiring surgical reintervention. Anastomotic leakage rates were somewhat higher in patients with a defunctioning stoma (9.3 vs. $10.4 \%$ ), but this difference was not statistically significant $(p=0.35)$. Fifteen of 302 patients who developed anastomotic leakage died during their hospital stay or within 30 days after surgery $(5 \%)$. Overall postoperative mortality rate was $1.8 \%(n=187)$; anastomotic leakage caused one-quarter of overall mortality. There was no difference in overall mortality rate between both groups- $1.3 \%$ in patients without stoma versus $2.1 \%$ in patients with stoma $(p=0.11)$.

\section{Hospitals}

Relevant case-mix factors were selected by backward stepwise logistic regression analysis. Relevant factors for the proportion of defunctioning stomas were sex, preoperative complications, tumor location, and laparoscopic surgery.

The hospitals' unadjusted proportion of defunctioning stomas varied considerably: percentages ranged from 0 to $100 \%$ (Fig. 1). Figure 2 shows the relation between the hospitals' adjusted proportion (O/E ratio) of defunctioning stomas and their overall anastomotic leakage rate (which varied from 3 to $18 \%$ ). There was a weak positive correlation between the hospitals' adjusted O/E stoma ratio and anastomotic leakage rates $(r=0.032)$, although this was not statistically significant $(p=0.76)$.

\section{Low Versus High Stoma Rate}

Eighteen hospitals with a total of 604 patients were identified as the group with low stoma rates. This group had a mean percentage of $26 \%$ of patients with a defunctioning stoma. The group with high stoma rates consisted of 18 hospitals, which treated 521 patients in total, and had an $88 \%$ mean defunctioning stoma rate (Fig. 3).

A slight difference in overall anastomotic leakage rates was found between groups, although this not statistically significant ( 8.4 vs.11.3\%; $p=0.11$ ). Severe anastomotic leakage rates were similar in both groups (7.1 vs. $7.5 \%$; $p=0.95$, while mild anastomotic leakage rates were significantly higher in the group with high stoma rates (1.5 vs. $3.8 \% ; p<0.001)$. Postoperative mortality rates were significantly higher in the group with high stoma rates (2.9 vs. $1.0 \% ; p=0.02)$. The remaining hospitals formed a group with intermediate stoma rates $(67 \%)$, and had outcomes between the low and high stoma groups $(9.7 \%$ anastomotic leakage, $1.7 \%$ mortality).

Table 2 shows the results of univariate and multivariate analysis for factors contributing to the odds of being in the group with high stoma rates. The percentage of patients treated with short-course radiation therapy (SCRT) was higher in the group with high stoma rates, as was the percentage of patients treated in teaching hospitals.

In addition, in multivariate analysis these patients had higher odds of being in the group with high stoma rates. In 
FIG. 1 Hospitals ranked by their casemix-adjusted defunctioning stoma rate. Based on quintiles, groups of low (left) and high (right) stoma rates were identified

FIG. 2 Adjusted defunctioning stoma $\mathrm{O} / \mathrm{E}$ rates of hospitals, plotted against their anastomotic leakage rates. $O / E$ observed/expected
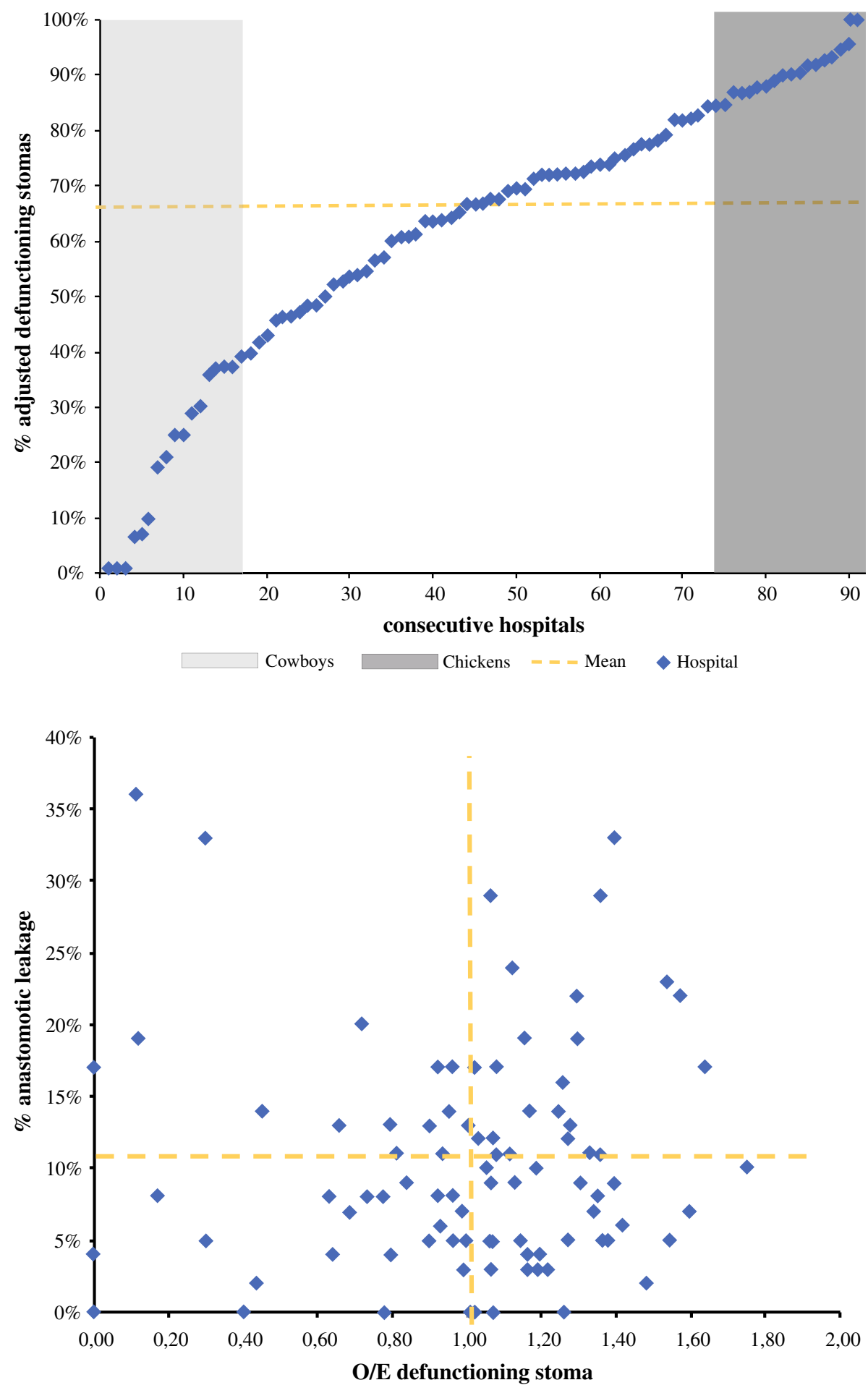

- - Mean both univariate and multivariate analysis, urgent resections and volume were associated with a lower risk of being treated in a hospital with a high stoma rate (Table 2). Other case-mix factors, such as age, ASA score and tumor characteristics, were not statistically different in both groups.

\section{DISCUSSION}

\section{Overview of Findings}

This study demonstrates a large variation between hospitals in treatment strategy concerning defunctioning stoma 
FIG. 3 Comparison of outcomes between the groups identified as low and high stoma rates. Results with an asterisk are considered statistically significant $(p<0.05)$

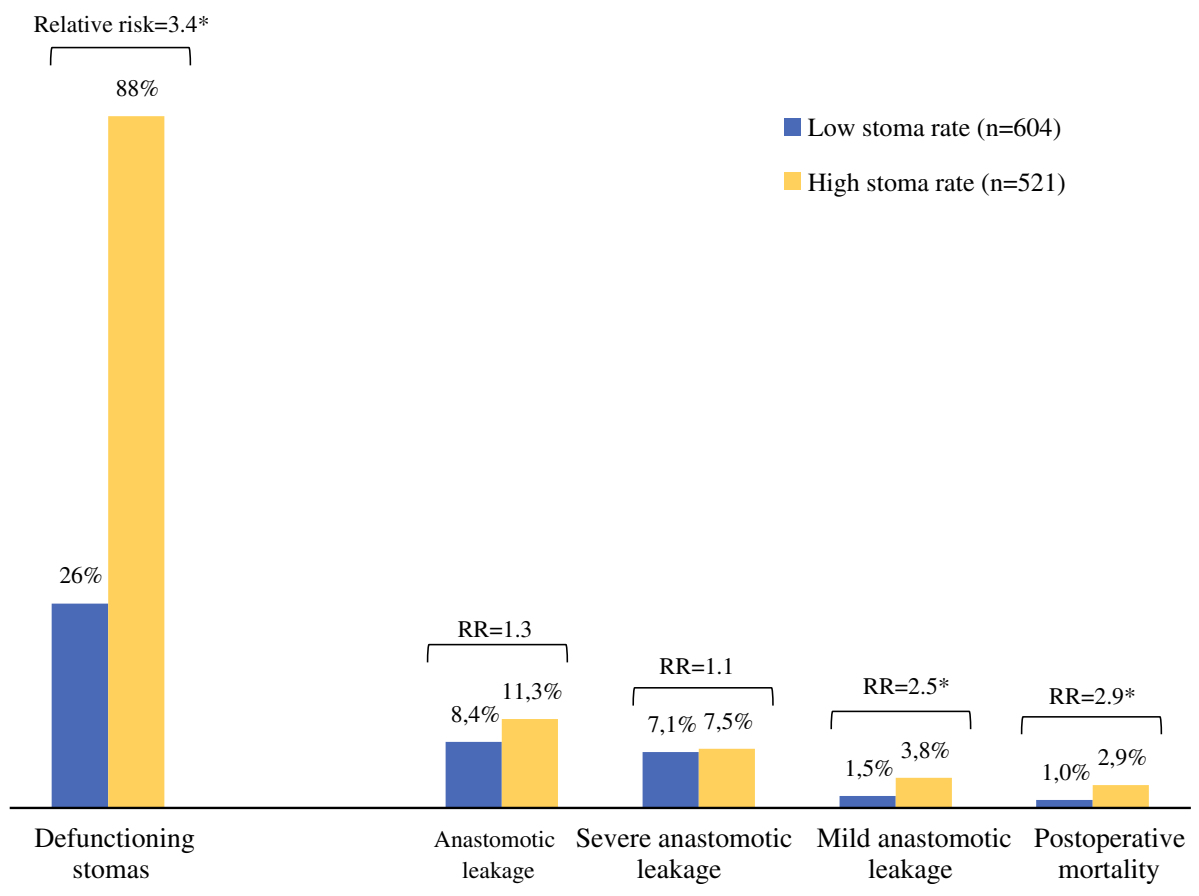

leakage rates. A meta-analysis from Hüser et al. ${ }^{1}$ mainly based on the results of a randomized controlled trial from Matthiessen et al. ${ }^{2}$ clarifies the advantage of a defunctioning stoma on lowering anastomotic leakage rates. This is confirmed by a number of retrospective studies. ${ }^{4,27-29}$ On the contrary, a study from Fielding et al. ${ }^{30}$ observed a higher leakage rate in patients with a defunctioning stoma (18 vs. $7 \%$ ) and suggested that surgeons with an individual anastomotic leakage rate less than $5 \%$ do not need to create a defunctioning stoma at all. Both Enker et al. and Matthiessen et al. showed that a defunctioning stoma did not reduce the incidence of anastomotic leakage in patients undergoing low or ultralow anterior resection. ${ }^{7,31}$

\section{Strengths and Limitations of the Study}

We retrospectively evaluated a prospectively maintained, population-based database to determine the association between the hospitals' strategy regarding defunctioning stoma construction and postoperative outcome in rectal cancer. It could be argued that comparing patient outcomes for patients with and without a stoma is not valid because of confounding by indication; patients may have received a stoma because they were considered to be high risk patients and are therefore not comparable to patients who did not receive a defunctioning stoma. This bias could also explain the relatively high mortality in the group with high stoma rates; however, in our study this bias is largely overcome by comparing hospitals at both ends of the spectrum (either very high or very low defunctioning stoma rates). Defunctioning stoma rates of 88 and $26 \%$,

after low anterior resection to decrease anastomotic 
TABLE 2 Univariate and multivariate analysis for factors contributing to being in the group with high stoma rates

\begin{tabular}{|c|c|c|c|c|}
\hline \multirow[t]{2}{*}{ Factor } & \multicolumn{2}{|l|}{ Univariate } & \multicolumn{2}{|c|}{ Multivariate } \\
\hline & Cowboys $[n(\%)]$ & Chickens $[n(\%)]$ & $\mathrm{OR}^{\mathrm{a}}$ & $95 \% \mathrm{CI}$ \\
\hline Age, mean & 66 & 66 & 0.99 & $0.98-1.01$ \\
\hline Female sex & $247(41)$ & $210(40)$ & 0.88 & $0.68-1.14$ \\
\hline \multicolumn{5}{|l|}{ ASA score } \\
\hline 1 & $157(30)$ & $149(30)$ & 1.0 & Ref \\
\hline 2 & $297(56)$ & $307(60)$ & 1.13 & $0.76-1.36$ \\
\hline $3+$ & $79(15)$ & $52(10)$ & 0.81 & $0.55-1.30$ \\
\hline \multicolumn{5}{|l|}{ Urgency } \\
\hline Urgent operation & $18(4)$ & $4(0.8)$ & 0.29 & $0.09-0.89$ \\
\hline Preoperative surgery, yes & $24(4)$ & $25(5)$ & 1.19 & $0.64-2.24$ \\
\hline \multicolumn{5}{|l|}{ T stage $(\mathrm{p})$} \\
\hline T0 & $22(4)$ & $32(7)$ & 1.0 & Ref \\
\hline $\mathrm{T} 1$ & $53(9)$ & $55(11)$ & 1.35 & $0.36-5.00$ \\
\hline $\mathrm{T} 2$ & $193(32)$ & $165(32)$ & 1.02 & $0.29-3.61$ \\
\hline $\mathrm{T} 3$ & $314(52)$ & $260(50)$ & 1.08 & $0.31-3.78$ \\
\hline $\mathrm{T} 4$ & $22(4)$ & $9(2)$ & 0.62 & $0.14-2.74$ \\
\hline Abdominal surgical history, yes & $135(22)$ & $144(28)$ & 1.26 & $0.94-1.70$ \\
\hline Tumor distance-anal verge, $>10 \mathrm{~cm}$ & $225(37)$ & $137(33)$ & 0.87 & $0.66-1.14$ \\
\hline Neoadjuvant therapy, none & $171(28)$ & $100(19)$ & 1.0 & Ref \\
\hline \multicolumn{5}{|l|}{$5 \times 5$} \\
\hline $5 \times 5 \mathrm{~Gy}$ & $301(50)$ & $308(60)$ & 1.67 & $1.20-2.31$ \\
\hline Chemoradiation & $132(22)$ & $133(22)$ & 1.13 & $0.72-1.69$ \\
\hline Surgical treatment, laparoscopy & $291(50)$ & $286(55)$ & 1.09 & $0.84-1.41$ \\
\hline Hospital type, teaching & $259(43)$ & $269(52)$ & 2.88 & $2.04-4.10$ \\
\hline \multicolumn{5}{|l|}{ Volume } \\
\hline$<25$ & $191(32)$ & $141(27)$ & 1.0 & Ref \\
\hline $25-50$ & $222(36)$ & $274(53)$ & 1.18 & $0.86-1.62$ \\
\hline$>50$ & $191(32)$ & $106(20)$ & 0.27 & $0.17-0.43$ \\
\hline
\end{tabular}

Bolded data indicate statistically significant $(p<0.05)$

$O R$ odds ratio, $C I$ confidence interval, ASA American Society of Anesthesiologists

${ }^{a}$ ORs display the odds for being in the group with high stoma rates

respectively, reflect a strategic approach (standard with a stoma or standard without a stoma), which is only slightly based on individual decision making concerning patient characteristics. It is likely that only very high risk patients received a stoma in both groups, and very low-risk patients in both groups did not. For other patients, the decision was mainly based on the strategic approach of the hospitals. Therefore the method we used resembles a 'pseudo randomization'. This is supported by the fact that baseline characteristics were similar for both groups in our study.

These findings are very useful for clinical practice because they strengthen the concept that the decision of stoma formation after anterior rectal resection cannot be standardized but requires careful evaluation of individual risk factors. Data represent current surgical practice at a population level since all hospitals participate in the DSCA and the percentage of eligible patients registered is over $90 \%$.

A limitation of this study is that analyses were performed at a hospital level, while the surgical strategy may differ between surgeons within a hospital. Information on a surgeons' level is not available in the DSCA and individual volumes may be low, introducing more impact of chance variation in the analyses.

\section{Clinical Implications}

Should we then be cowboys or chickens, if the latter does not necessarily result in better outcomes? The results confirm that the protective effect of a defunctioning stoma is probably most apparent in high-risk patients, while the 
additional benefit for the rest of the population is limited or even non-existent. There have been numerous studies identifying risk factors for anastomotic leakage. ${ }^{9-13}$ Dekker et al. developed and tested the colon leakage score (CLS) in which multiple risk factors were used to provide an objective prediction of the risk for anastomotic leakage. ${ }^{32}$ They found that only $20 \%$ of their population could be considered as high risk. If we take into account the relative risk reduction of $64 \%$ that was found in the randomized trial of Matthiessen et al. (reduction in anastomotic leakage from 28 to $10 \%$ ) for high-risk patients with an hypothetical a priori risk of anastomotic leakage of $20 \%$, this would mean an absolute risk reduction (ARR) of $12.8 \%$, and therefore eight defunctioning stomas would have to be constructed in order to prevent one anastomotic leak. In contrast, for patients with an a priori risk of $5 \%$ (ARR $3.2 \%), 31$ defunctioning stomas would have to be created to prevent one leak.

It should therefore be kept in mind that stomas can induce morbidity, discomfort (quality of life), costs, and even mortality. Stomal complications cause readmission within 2 months after initial surgery in up to $17 \%$ of all patients, mostly due to dehydratation. ${ }^{9,11,33,34}$ Even when a defunctioning stoma is constructed, there is still a considerable risk of (late) anastomotic leakage ${ }^{2,4,35-37}$ A recent study from our group on 1-year follow-up data shows a significant higher morbidity rate in patients with a defunctioning stoma when compared with patients without, due to unplanned readmissions $(18 \%)$ and reinterventions $(12 \%)$ caused by anastomotic leakage and drainage of abscesses. ${ }^{37}$ It is also recognized that 15-30\% of defunctioning stomas are never closed, resulting in a permanent stoma. ${ }^{10,38}$ Future studies are important to gain more evidence on the possible benefits of defunctioning stomas in high- and low-risk patients.

Finally, we advocate that patients' preferences concerning the risk of morbidity and mortality of anastomotic leakage versus the consequences of a defunctioning stoma should be taken into account preoperatively.

\section{CONCLUSIONS}

A high tendency towards defunctioning stoma construction in rectal cancer surgery did not result in lower overall anastomotic leakage or mortality rates. The optimal treatment strategy can probably be found in hospitals with both low stoma rates and favorable postoperative outcomes. It seems that hospitals with low stoma rates were better in selecting high-risk patients, and that stoma formation in more patients does not lead to better outcomes.

Adequate identification of high-risk patients should be the focus of future studies in order to facilitate decision making.
ACKNOWLEDGMENTS The authors would like to thank all surgeons, registrars, physician assistants, and administrative nurses who registered all the patients in the DSCA, as well as the DSCA Group and the Methodological Board for their advice.

\section{DISCLOSURE None.}

Open Access This article is distributed under the terms of the Creative Commons Attribution License which permits any use, distribution, and reproduction in any medium, provided the original author(s) and the source are credited.

\section{REFERENCES}

1. Hüser N, Michalski CW, Erkan M, et al. Systematic review and meta-analysis of the role of defunctioning stoma in low rectal cancer surgery. Ann Surg. 2008;248:52-60.

2. Matthiessen P, Hallbook O, Rutegard J, Simert G, Sjodahl R. Defunctioning stoma reduces symptomatic anastomotic leakage after low anterior resection of the rectum for cancer: a randomized multicenter trial. Ann Surg. 2007;246:207-14.

3. den Dulk M, Marijnen CA, Collette L, et al. Multicentre analysis of oncological and survival outcomes following anastomotic leakage after rectal cancer surgery. Br J Surg. 2009;96:1066-75.

4. Peeters KC, Tollenaar RA, Marijnen CA, et al. Risk factors for anastomotic failure after total mesorectal excision of rectal cancer. Br J Surg. 2005;92:211-16.

5. Snijders HS, Wouters MW, van Leersum NJ, et al. Meta-analysis of the risk for anastomotic leakage, the postoperative mortality caused by leakage in relation to the overall postoperative mortality. Eur J Surg Oncol. 2012;38:1013-19.

6. Koperna T. Cost-effectiveness of defunctioning stomas in low anterior resections for rectal cancer: a call for benchmarking. Arch Surg. 2003;138:1334-38.

7. Matthiessen P, Hallbook O, Andersson M, Rutegard J, Sjodahl R. Risk factors for anastomotic leakage after anterior resection of the rectum. Colorectal Dis. 2004;6:462-69.

8. Saha AK, Tapping CR, Foley GT et al. Morbidity and mortality after closure of loop ileostomy. Colorectal Dis. 2009;11:866-71.

9. Nastro P, Knowles CH, McGrath A, Heyman B, Porrett TR, Lunniss PJ. Complications of intestinal stomas. $\mathrm{Br} J$ Surg. 2010;97:1885-89.

10. den Dulk DM, Smit M, Peeters KC, et al. A multivariate analysis of limiting factors for stoma reversal in patients with rectal cancer entered into the total mesorectal excision (TME) trial: a retrospective study. Lancet Oncol. 2007;8:297-303.

11. Harris DA, Egbeare D, Jones S, Benjamin H, Woodward A, Foster ME. Complications and mortality following stoma formation. Ann R Coll Surg Engl. 2005;87:427-31.

12. Pachler J, Wille-Jorgensen P. Quality of life after rectal resection for cancer, with or without permanent colostomy. Cochrane Database Syst Rev. 2004;2:CD004323.

13. Floodeen H, Lindgren R, Matthiessen P. When are defunctioning stomas in rectal cancer surgery really reversed? Results from a population-based single center experience. Scand J Surg. 2013;102:246-50.

14. Dikken JL, Wouters MW, Lemmens VE, et al. Influence of hospital type on outcomes after oesophageal and gastric cancer surgery. Br J Surg. 2012;99:954-63.

15. Elferink MA, Wouters MW, Krijnen $P$, et al. Disparities in quality of care for colon cancer between hospitals in the Netherlands. Eur J Surg Oncol. 2010;36(Suppl 1):S64-73. 
16. Goossens-Laan CA, Visser O, Wouters MW, et al. Variations in treatment policies and outcome for bladder cancer in the Netherlands. Eur J Surg Oncol. 2010;36(Suppl 1):S100-07.

17. van Steenbergen LN, van de Poll-Franse LV, Wouters MW, et al. Variation in management of early breast cancer in the Netherlands, 2003-2006. Eur J Surg Oncol. 2010;36(Suppl 1):S36-43.

18. Wouters MW, Siesling S, Jansen-Landheer ML, et al. Variation in treatment and outcome in patients with non-small cell lung cancer by region, hospital type and volume in the Netherlands. Eur J Surg Oncol. 2010;36(Suppl 1):S83-92.

19. de Munck L, Visser O, et al. Variation between hospitals in surgical margins after first breast-conserving surgery in the Netherlands. Breast Cancer Res Treat. 2012;131:691-98.

20. Paul-Shaheen P, Clark JD, Williams D. Small area analysis: a review and analysis of the North American literature. J Health Polit Policy Law. 1987;12:741-809.

21. McPherson K, Wennberg JE, Hovind OB, Clifford P. Small-area variations in the use of common surgical procedures: an international comparison of New England, England, and Norway. $N$ Engl J Med. 1982;307:1310-14.

22. van der Sanden GA, Coebergh JW, Schouten LJ, Visser O, van Leeuwen FE. Cancer incidence in The Netherlands in 1989 and 1990: first results of the nationwide Netherlands cancer registry. Coordinating Committee for Regional Cancer Registries. Eur J Cancer. 1995;31A:1822-29.

23. Kapiteijn E, Marijnen CA, Nagtegaal ID, et al. Preoperative radiotherapy combined with total mesorectal excision for resectable rectal cancer. N Engl J Med. 2001;345:638-46.

24. Snijders HS, van den Broek CB, Wouters MW, et al. An increasing use of defunctioning stomas after low anterior resection for rectal cancer. Is this the way to go? Eur J Surg Oncol. 2013;39:715-20.

25. Sebag-Montefiore D, Stephens RJ, Steele R, et al. Preoperative radiotherapy versus selective postoperative chemoradiotherapy in patients with rectal cancer (MRC CR07 and NCIC-CTG C016): a multicentre, randomised trial. Lancet. 2009;373:811-20.

26. Chang JS, Keum KC, Kim NK, et al. Preoperative chemoradiotherapy effects on anastomotic leakage after rectal cancer resection: a propensity score matching analysis. Ann Surg. 2014; 259:516-21.
27. Poon RT, Chu KW, Ho JW, Chan CW, Law WL, Wong J. Prospective evaluation of selective defunctioning stoma for low anterior resection with total mesorectal excision. World J Surg. 1999;23:463-67.

28. Eriksen MT, Wibe A, Norstein J, Haffner J, Wiig JN. Anastomotic leakage following routine mesorectal excision for rectal cancer in a national cohort of patients. Colorectal Dis. 2005;7:51-7.

29. Lefebure B, Tuech JJ, Bridoux V, et al. Evaluation of selective defunctioning stoma after low anterior resection for rectal cancer. Int J Colorectal Dis. 2008;23:283-88.

30. Fielding LP, Stewart-Brown S, Blesovsky L, Kearney G. Anastomotic integrity after operations for large-bowelcancer: a multicentre study. Brit Med J. 1980;281(6237):411-14.

31. Enker WE, Merchant N, Cohen AM, et al. Safety and efficacy of low anterior resection for rectal cancer: 681 consecutive cases from a specialty service. Ann Surg. 1999;230:544-52.

32. Dekker JW, Liefers GJ, de Mol van Otterloo JC, Putter H, Tollenaar RA. Predicting the risk of anastomotic leakage in left-sided colorectal surgery using a colon leakage score. J Surg Res. 2011;166:e27-34.

33. Messaris E, Sehgal R, Deiling S, et al. Dehydration is the most common indication for readmission after diverting ileostomy creation. Dis Colon Rectum. 2012;55:175-80.

34. Chun LJ, Haigh PI, Tam MS, Abbas MA. Defunctioning loop ileostomy for pelvic anastomoses: predictors of morbidity and nonclosure. Dis Colon Rectum. 2012;55:167-74.

35. Gastinger I, Marusch F, Steinert R, Wolff S, Koeckerling F, Lippert $\mathrm{H}$. Protective defunctioning stoma in low anterior resection for rectal carcinoma. Br J Surg. 2005;92:1137-42.

36. Pakkastie TE, Ovaska JT, Pekkala ES, Luukkonen PE, Jarvinen HJ. A randomised study of colostomies in low colorectal anastomoses. Eur J Surg. 1997;163:929-33.

37. Snijders HS, Bakker IS, Dekker JW, et al. High 1-year complication rate after anterior resection for rectal cancer. J Gastrointest Surg. 2014;18:831-38.

38. Gooszen AW, Geelkerken RH, Hermans J, Lagaay MB, Gooszen HG. Temporary decompression after colorectal surgery: randomized comparison of loop ileostomy and loop colostomy. $\mathrm{Br} \mathrm{J}$ Surg. 1998;85:76-9. 